origin of phthisis still assumes as unquestionable that which is more and more doubted as the science of animal and vegetable morphology adrances. The cell theory of Schleiden and Schwann is every day less and less implicitly received! If this theory should be demolished, Dr. Smith's hypothesis will "leave not a rack behind" to bear even a sepulchral witness to the credulity of its author! If Mr. Wenham's recently published views with reference to the mechanism of cell-formation should be confirmed by the march of discovery, Dr. Smith's hypothesis will become at once a "dissolving view !" If, by the progress of correct observation, the highly philosophical and probable opinions of Wedl in relation to cancer and its varieties should receive further support, Dr. Smith's speculations will lose at once all bodily form!

The preceding criticism I offer with the utmost respect. Dr. Smith is capalle of better things than his " Theory of Phthisis." He may rest assured that his speculations will conduct him further and further away from that pathway of cautious induction, along which the correct thinker on such a subject as that on which he writes should even desire to travel. He seems very skilled in weaving one vision into another. But I think that any earnest student, who during the last few years has followed the current of discovery in organic chemistry, normal histology, and pathological morphology, will agree with me, that in the present remarkably transitional state of physiological and pathological knowledge, no living man can summon to his presence adequate materials for the coustruction of even a probable theory either of tuberculosis or cancer.

\section{ON CHOLERA: ITS DIAGNOSIS AND TREATMENT.}

By C. W. Bell, M.D., K.L.S., late Physician to H.M. Embassy in Persia, etc., Buxton, Derbyshire.

WEARY though most people are of the very name of cholera, it appears a duty to take advantage of the comparative immunity this country has enjoyed from that disease during the past year as a more favourable time for dispassionately considering the information we possess respecting it, than either while it is present, or its advent apprehended.

I have devoted much leisure to the perusal of recent contributions to the literature of the subject, as well as of works considered by the profession as authorities, and truly a less satisfactory course of reading could hardly be pointed out. So varied are the views adopted by different authors, that, though it was at first my intention to try to elicit truth by a process of exclusion, reviewing opinions and rejecting what appeared untenable or illogical, I soon became satisfied that no one would consent to wade through such a mass of inconsequential lucubration as this plan would have entailed upon the resuler, or have the patience to inquire how conclusions the most opposite, arrived at by authors, according to the point of view from which their opportunities permitted them to survey the disease, were capable of being reconciled like the celebrated dispute of the two knights who each saw only one side of the shield. In many of these treatises, it might even be doubted, but for the title-page, whether we had not by mistake taken up a work on a totally different subject instead of one on cholera asphyxia, maligna, Asiatica, algida-for such are the recognised epithets bestowed on the disease in question. Upon the whole, therefore, it appeared the preferable course, as being the only one that would admit of the whole subject being brought within reasonable bounds, altogether to abstain from the citation of authorities, and to trust instead to the readers' knowledge of individual opinions when such are alluded to, and of the facts which I have made the basis of my argument.

A careful examination of the literature of cholera has satisfied me that more than one disease essentially distinct in nature, cause, course, and character, has been described under that name; and until this be fully admitted by the profession, we must despair of arriving at any settled conclusions with regard to its true nature and treatment. The evil that existed in 1831, when all Europe was turning with alarm to the East to wateh the progress of the coming pestilence, still remains un diminished-we mean, the want of a definition of cholera : nor is it a definition only that is wanted, for strange and incredible as it may appear, there is not one single symptom, circum. stance, or condition of the system, that all authors concur in describing as invariably present in an attack of this malady. It is a source of no small disappointment that no new light has been shed on this disease by the most recent work on the diseases of India (Clinical Researches on Disease in India, by Charles Morehead, M.D.: 1856); I had looked with eager expectation to its appearance, in the hope that the distinctions which I am about to attempt to draw from reason might there have been established by practical authority.

The nearest approach which I can find in all the various descriptions of the disease to agreement in noticing any single symptom as characteristic, is a kind of general admission of the existence of a remarkable condition of the circulation and of the blood in bad cases. It signifies little to my purpose that very different degrees of importance are attributed to this condition of the circulation in cholera, as a symptom, and that very different opinions are entertained as to its cause. It is much to be able to fix upon even one fact admitted by the majority as constant in this disease.

A review of the whole subject would justify the conclusion that this peculiarity consists not in primary poisoning or alteration of the blood, but in a species of paralysis of the powers which circulate the blood, and such a change in the action of the capillaries as respects nutrition, secretion, and the evolution of animal heat, as can only be referred to disorder or cessation of the agency which the sympathetic system of nerves is acknowledged to exert over these functions in health; but were we to attempt to go into the proof of this before the subject has first been disencumbered of those forms of disease which have been mistakenly described as cholera, we should only be plunging once more into that abyss of darkness and confusion we are so anxious to struggle out of.

Let us, then, in the first place, atternpt to distinguish in the different maladies described as cholera all such symptoms as do not essentially belong to its purely congestive form which we regard as the type of the disease, and refer each of them to its true cause, in order that we may perfect our diagnosis, and clearly perceive the rationale of the treatment required in each several instance.

Almost all climates, but especially the more tropical, are liable to epidemics of diarrhœa, which attack very suddenly. These very often commence as hepatorrhoea (if the term be permitted), a copious pouring out of irritating bile. This in hot climates commonly induces inflammatory ulceration in the glands of the colon in the course of a few hours, and the case becomes one of confirmed dysentery. In this climate a similar hepatorrhœa, attacking as suddenly, is what we call English cholera; but here, instead of inducing dysentery, it generally passes off without mischief after the bile has been evacuated by plentiful vomiting and purging.

Of this nature, too, is a large proportion of the cases of diar rhœe which occur every autumn, and which in general attract very little attention; but if cholera of the true congestive type occur at the same season, all such attacks are then termed cases of premonitory diarrhøea; not because this condition necessarily, and in all cases, precedes cholera, but because a tendency to bowel complaint of any kind becomes in times when that disease breaks out epidemically, a predisposing cause of great power to induce an attack of algide cholera.

'The fact is well known, that even slight attacks, such as at other times would be thought too trivial to require attention, are liable, if neglected, to lie quickly followed by symptoms of fatal collapse when cholera is epidemic ; but to cure this diarrhœa, and so guard the patient from becoming the subject of that epidemic influence, is quite a different matter from curing cholera. Too many people's ideas are governed by a name. The title of premonitory diarrhœa, given by authority to such affections, is considered by many to denote that such diarrhœe is an actual stage of cholera; and the practitioner who uses the term in that sense naturally concludes that in curing the purging with a little chalk, or lead and opium, he has cured a case of cholera. This is one of the greatest sources of error and confusion; for in the great majority of cases called "premonitory", the diarrhœa has in the first instance no connexion whatever with true cholera. The most ordinary means will arrest it; but this must be done at once, for if allowed to proceed, the disturbance of the circulation by excessive intestina secretion, as well as that it produces on the whole sympathetic system, will very soon so invalidate vital resistance to the epidemic influence, that algide cholera is superinduced.

It is necessary here to observe, that cholera is not the only disease capable of being superinduced on simple diarrhuea. It is true that in this country we can hardly conceive the devastation suddenly spread over a whole district by the invasion of epidemic dysentery, to which the slightest disturbance of the bowels will then give rise; and we read of idiopathic peritonitis having been similarly epidemic, and its attacks connected with 
intestinal derangement: but further illustration is unnecessary, for there are probably few medical men who have had extensive dispensary practice, or much to do with the poor in their own dwellings, who have not seen English cholera become dysentery; and that dysentery, in foul neighbourhoods, become highly contagious and endemic, in combination with putrid or typhoid fever. In these cases, there appears reason to believe that the disease is communicated almost entirely by means of the condensation of putrid particles in a state of great chemical activity, in water, milk, the saliva, or other fluid exposed to the effluvia of the exuvies; and that these particles, when imbibed, have the power of inducing the same putrefactive action in the mucus of the stomach and bowels, and of converting it into an irritant poison, producing effects like those of croton oil, and continually reproducing itself. This is a fact which the observations of Dr. Snow and his followers seem fully to have established. They have brought a vast amount of evidence together to show what a pregnant source of choleraic diarrhœa water is, when among other impurities it contains the smallest quantity of fæcal matter; or, more accurately, of intestinal mucus in a state of active decomposition. It would also appear probable from the same evidence that, where the choleraic atmosphere exists, such mucus is prone to assume an activity of putrescence not common at other times, or else that the emollient mucus of the bowels is then more than usually predisposed to be acted upon by a putrefactive excitor imbibed.* Be that as it may, however, there can be no doubt of the communicability of a putrid form of diarrhœa from the sick to the healthy, of which the following is an instance.

A woman, living in a cellar in Manchester, into which an open grid communicated with the drain, was attacked with diarrhoea; she died. Her daughter, then suffering, was sent into hospital; she too died, but introduced a most virulent diarrhøa into the ward, of which one of the women who lay in the bed next her died, and the other neighbour escaped only with life. The father at the same time, being crippled with rheumatism, was removed to the workhouse, where he died, and there also infected many with this putrid diarrhœa. In none of these cases was there the slightest symptom of an algide character. There was no Asiatic cholera prevalent that year. Had it been otherwise, probably every one attacked, as well those who recovered as those who died, would have sank into fatal collapse, and would have presented all the usual symptoms of the worst cases of cholera. The cases $I$ have given, though of a more than usually virulent character, are by no means rare; and there is probably no filthy neighbourhood in the purlieus of a large town but can furnish similar instances of contagious diarrhœa every autumn.

It may seem unnecessary here to repeat that neither this putrid diarrhœa, nor some other kinds, however fatally they may predispose to collapse wherever algide cholera has appeared, are truly cholera; for they occur alike where cholera is, and where it is not, and multitudes recover or die without ever having exhibited a single symptom of that paralysed state of the eirculation which is known as collapse, and is pathognomonic of algide cholera. These facts, however, only render it the more incumbent on us to study with care the source and ratio medendi of any prevailing tendency to diarrhœa whatever, that may exist where cholera declares itself, in order that by warding off this powerful source of debility from the sympa. thetic system, we may preserve sufficient nervous energy to resist the influence of the epidemic to which continued purging would otherwise so powerfully predispose it to succumb. Thus a practitioner in the tropics, who has mostly to deal with bilious diarrhœe, trusts to calomel and opium as his sheet anchor, and with it, he conceives, he cures the cholera ; the same treatment answers very well in this country when cholera breaks out in the autumnal months; still even its champions allow that mer. cury has appeared in some instances to have brought on, rather than to have warded off, algide symptoms; and that, however successful the practice in general is, there do occur cases in which it does no good, and where in spite of its fullest exhibition the mildest attacks have ended fatally. Some have confidence only in sugar of lead and opium, but the same com. plaints are made of it as of calomel, that it is inapplicable where there is no purging (that is to say, in the purely con-

* The effects of putrefactive excitors on the secretions of various membranes, converting them into irritants and sources of inflammation of the membranes-e.g., of the urethra, conjunctiva, nares, mouth, intestines, the pleura or peritoneum, or the lining membrane of the veins-which is probably the true source of what Hunter calls continuous sympathy, requires latter part of Dr. Bell's " Address in Medicine".-Prov. Med. and Surg. latter part of Dr. Bell
Trans., 1850, vol. xvii.) gestive form), and does not suit every epidemic of the disease equally well.

Some authors who have mainly had to do with the putrid diarrhœa occurring in the purlieus of large towns, or in neighbourhoods supplied with impure water, have described that disease as cholers, into which since 1831 it has frequently lapsed. It has been found that deluging the bowels with castor oil cures this complaint, and the superinduced symptoms of algide cholera often disappear on the cessation of the diarrhœa; an attentive perusal, however, of the fatal cases, in which the failure of the remedy is attributed to the carelessness of the nurse, will convince the reader that these were of a totally different nature from those in which the medicine proved effectual. This is the form of diarrhœa which is often termed in India village cholera, as being engendered by filth, and distinguished by its prolonged premonitory character and apparent contagiousness, from the rapid congestive form generally met with on a march, and it is that which European authors mainly treat of as breaking out in densely peopled towns and villages. Its putrid origin requires an antiseptic treatment, and there is scarcely a substance of that nature that has not been extolled as a panacea for a time, e.g., dilute sulphuric acid, nitric acid, nitrate of silver, the oxides of almost all the metals, finely powdered charcoal of peat or soft woods. aromatic gums and essential oils, have all been vaunted for their efficacy; we find, however, that the majority of cases cured by such means had never reached the stage of collapse, or had so slightly succumbed to that influence as to throw it off so soon as the diarrhœa was cured. On the other hand, we read in almost every work on the subject, of isolated cases so virulent that they sank into collapse at once without having had diarrhœa at all, or perhaps only a single purging.

Among the various kinds of diarrhœa which may prevail contemporaneously with epidemic cholera, there is one which it is particularly necessary to distinguish from those produced by bilious derangement or arising from foul water, because it is in fact true cholera, and will be materially aggravated by calomel and opium, will be in noways benefited by antiseptics, whereas drastic purgatives would be almost certain to convert this mild attack into fatal congestion. This may be called intermittent diarrhon, a painless purging of a colourless, inodorous fluid, lasting for an hour or two each day, then ceasing till the same hour on the day following. This form is frequently to be remarked as preceding an epidemic of cholera by a few weeks, but never met with unless that disease be actually present or in the neighbourhood. 'This kind of purging sometimes goes on for a week or more, but it is rare for it to continue for more than three days without being attended with some more serious symptom. The appearance of the patient when the hour of attack approaches is characteristic. The eyes sunk, the lips livid, the nails purple, with an aguish streak upon them; the veins of the backs of the hands contracted like ink lines traced with a pen; and the tongue perfectly clean and pale, as if macerated. The dejections are unaccompanied with pain or griping. The urine is commonly scanty and of a dark porter-like colour, and pressure over the spleen causes pain.

A few doses of a grain or two of quinine and sulphate of iron arrest this at once, and the medicine is felt to be grateful to the whole system; whereas in the bilious and putrid forms of diarrhœa such a dose would prove both nauseous and injurious. But it may be asked, granting the importance of distinguishing between these three kinds of diarrhuea (and as many more as may be), in order to ennble us to treat them so as most effectually to prevent the accession of algide symptoms, what after all is the difference between them after the algide symptoms have commenced? In all of them the lips are then livid, the eyes sunk, the nails blue, the pulse feeble or imperceptible, the extremities like wet leather, and they suffer more or less from cramps. Is there any essential difference in these apparently identical cases now, such as to require different treatment? And if so, how are the cases to be distinguished from one another after having reached this stage? This is, in fact, the material point in question; for if such a difference in symptoms can be distinguished as to imply the necessity for totally different treatment, the enigma which Asiatic cholera has everywhere presented to those who have written upon it, or tried to com. prehend its nature or its cure, will be solved.

With respect to the putrid dysentery, after algide symptoms have commenced, there is no difficulty whatsoever in distinguishing it by the smell alone; for, on turning down the bedclothes, the nose is assailed with the most sickening odour of bad size or putrid soup-not at all feculent in smell, but pecu- 
liar, and never to be forgotten. The purging is an incessant squirting of this foul fluid. If any doubt exist, let a dose of quinine and iron be given, and the disgust expressed will attest the nature of the attack. The other diagnostic signs are, that there is always some fur on the tongue, the pulse is generally perceptible, and the heart's action very rapid and feeble; not convulsively struggling and churning as in congestive cholera. Add to this that some urine is generally. secreted, the extremities are not so cold as in the congestive disease, nor does the same amount of warmth return to them when death takes place. The previous history of the attack is, that the patient has been purged perhaps a dozen times within a few hours; at first the tongue was red and much furred, the mouth hot, the skin warm, the pulse above a hundred and sharp; then sickness came on and cramps, the skin grew cold and damp, and, exhausted by continued purging, he has fallen into the state of collapse.

It is, in the first place, of importance here to remark, that there is nothing of that oppression of the heart's action by excess of blood on the right side, and deficiency of it on the left, which to relieve is to cure, in the congestive form of cholera.

The continued purging, which is here a secretion, not an exudation, prevents that overdistension of the great venous trunks of the cava and portal system taking place, which obstructs secretion. In short, it is not venous congestion and paralysis of action in the capillaries that we have to contend with here, but a draining away of the life by the quantity of fluid poured into the bowels under the influence of the putrid irritant into which the whole of the mucus of the intestines has been converted. It is in vain that we here attack the algide symptoms, for even were we successful in restoring animal heat, etc., the cause remains; and as long as mucus continues to be secreted into the bowels, the purging will continue unless the putrefactive action be arrested.

It seems probable that large draughts of finely powdered peat charcoal in water will ultimately be found the best cure for this malady. Dr. Johnson uses castor oil, which answers very well if repeated sufficiently perseveringly to evacuate the decomposing mucus as quickly as it is formed. Tartar emetic in combination with calonel answers very well, or calomel alone in repeated doses, where it acts both directly as an antiseptic and in the same purgative way as castor oil. Dilute sulphuric acid drink is purely antiseptic in its operations; so is salt; and cases are mentioned where an immense draught of spirits has cured. If by any of these means the putrescent action is arrested and the purging stopped, warmth gradually returns to the surface, and the algide symptoms disappear.

It may be observed, that correct diagnosis alone can direct the cure here, for to attempt this by the means which afford the greatest relief to patients suffering from the congestive or true form of the disease only aggravates; and indeed the expression of disgust and horror exhibited by patients in the algide state of cholera induced by putrid diarrhœa when offered a second dose of solution of quinine and iron, is in perfect contrast to the thankfulness with which a similar dose is swallowed by one in the congestive stage of true cholera.

Of the bilious form of diarrhœa after algide symptoms have been superinduced, I find innumerable cases cited by Indian authorities, for example, 'Twining, Parkes, and others. In the first stage the attack is identical with that which, were cholera absent, would turn to dysentery; and most of the protracted cases exhibit dysenteric symptoms, if the algide stage be reco. vered from, along with remittent or so-called consecutive fever. Here there is no very leading symptom, unless it be the presence of a very little fur on the tongue, which is never seen in pure congestive cholera, and the absence of putrid odour on throwing down the bedclothes. The purging is very considerable in quantity, generally colourless and without smell, save when occasionally it contains bile. The treatment here is strictly that applicable to acute dysentery : calomel and opium, ipecacuanha, sugar of lead and opium, etc. Mere antiseptics, like dilute sulphuric acid, do no good; and the draught of quinine and iron, though not producing the intensity of disgust that it does in cases of putrid diarrhoea, is disagreeable to the patient, and is attended with none of the sensations of comfort and relief afforded by its exhibition in purely congestive cholera. In these cases all the adjuncts of treatment by hot air baths, stimulants, etc., may be found of value which in true congestive cholera are exactly the reverse : perhaps where the distinction is otherwise difficult, the tolerance of warm applications in the one case, and their extreme intolerance in the other, might serve as a test.

This is all that it has appeared necessary to premise respect- ing the diseases, which, though distinct from cholera in their essence, most frequently lead into it. Practically, they may perhaps be deemed of even greater importance than the unmixed congestive or primary disease, as being numerically more fatal.

[To be continued.]

\section{ON A POSSIBLE CAUSE OF THE FIRST SOUND OF THE HEART.}

By Johx Cockle, A.M., M.D.

I Have frequently meditated upon the assertion of Bartholini, made in his Anatomy, published in 1673, page 379, that the ligation of the venæ cavæ arrested the action of the heart. $\mathrm{He}$ writes: "Unico experimento fidem assertione facio, si vinculo intercipiantur vasa cordis adferentia motus cordis desinit, reliquusque erit undulans tantum motus et palpitatio, soluta ligatura motum recipit. Recentiores curiosi novo experimento nos confirmant."

Haller (Observation sur la Cause du Mouvement du Cour, 1751 ), in repeating this experiment, found, that unless the cava were opened, and the right auricle emptied, the motion of the heart was not always arrested, but that with the precaution in dicated the experiment was always successful.

These experiments then, in warm-blooded animals, fully demonstrate the presence of blood in the auricle to be the sine qua non of the heart's perfect systolic and diastolic motion.

Dr. Halford has more recently shown, by well devised experiment, that if the cavæ are compressed, although the heart's action continues vigorous, yet upon the application of the stethoscope "no sound whatever is heard."

I venture to suggest, therefore, taking these experiments as a basis, supported by others of my own, which I shall make the subject of a future paper, that the first sound may be principally produced in the following manner. During, at least, part of the time of the ventricular systole, the auriculoventricular valves are closed by the pressure of the column of blood impelled against them; but by the time the valves are brought to the plane of closure, the dilating auricles have allowed the blood streaming from the cavæ and pulmonary veins to form a layer upon the upper surface of the valves; and it is, I conceive, by the reaction of the lower column of blood upon the superimposed layer, the valve intervening that the special character of the first sound is produced. The modifications of the sound, in part, depending upon the varying quantity of blood entering the cavity of the auricles.

63, Brook Street, Grosvenor Square, January 24th, 1857.

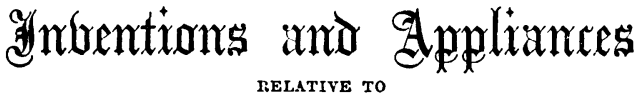

MEDICINE AND SURGERY.

\section{BOURJEAURD'S ELASTIC APPARATUS.}

THE difficulty of applying pressure, when required, to any part of the body, in such a way that it shall fully effect the object desired, without either positively or negatively doing mischief either to the parts under treatment or to those in their vicinity, has long been a source of annoyance to surgeons. Hence systematic writers on surgery are accustomed to lay down precise instructions as to the mode of bandaging a limb; and, in medical schools, a special course of instruction on this important branch of surgical practice is sometimes given.

In recent years, surgeons and mechanicians have endeavoured to make application of the elastic property of certain substances in this direction, and especially of caoutchouc or India rubber. Of those who have devoted their attention to this subject, Mr. BourJeaturd holds the most prominent position, and has contrived a number of elastic appliances which, although they may, on further experience, be found capable of improvement in some of their details, yet far surpass in efficiciency and safety the means formerly in use. It is right here to state, that Mr. Bourjeaurd has the advantage of not being a mere amateur mechanician; he is, in fact, a member of the 